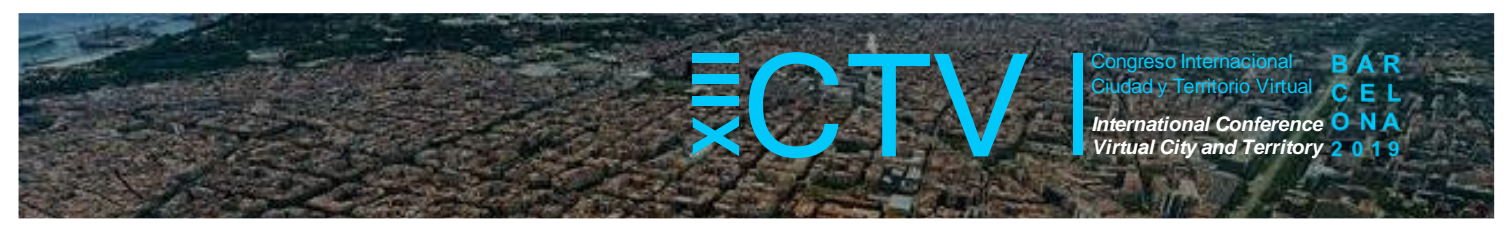

\title{
MODELO DE PLANIFICACIÓN URBANA COGNITIVA PARA UN PROTOTIPO DE ACCESO A LA VIVIENDA Y URBANISMO COLABORATIVOS
}

\author{
Jiménez-Pacheco, Pedro ${ }^{1 *}$; Puente Garrido, Diego ${ }^{2}$; Recalde, Lorena ${ }^{3}$ y Meza, Jaime ${ }^{4}$
}

Remisión inicial: 2019-06-07; Remisión definitiva: 2019-09-18; Publicación: 2019-12-21

Citación: Jiménez-Pacheco, P. et al. (2019). Modelo de planificación urbana cognitiva para un prototipo de acceso a la vivienda y urbanismo colaborativos. En XIII CTV 2019 Proceedings: XIII International Conference on Virtual City and Territory: "Challenges and paradigms of the contemporary city": UPC, Barcelona, October 2-4, 2019. Barcelona: CPSV, 2019, p. 8514. E-ISSN 2604-6512. DOI http://dx.doi.org/10.5821/ctv.8514

\begin{abstract}
Resumen
Considerando la situación actual de la vivienda, la débil participación en los procesos de planificación urbana y el estancamiento del sector de la construcción en Ecuador, el Proyecto de investigación interuniversitario "Planificación Urbana Cognitiva" se propuso como horizonte el desarrollo de un aplicativo web que promueva el urbanismo colaborativo en el marco de las ciudades cognitivas. Esta comunicación busca establecer los requerimientos funcionales urbanísticos (RFU) del modelo de planificación urbana cognitiva (MPUC) para el desarrollo del prototipo de un software de trabajo colectivo en tiempo real, que posibilite el acceso a la vivienda y el urbanismo colaborativo, como prácticas propulsoras de una planificación urbana renovada en las ciudades ecuatorianas de Quito y Portoviejo. La metodología de investigación se desarrolló en cinco momentos: i) Síntesis epistemológica de los resultados de la revisión sistemática de literatura (SLR); ii) revisión de un modelo parcial de planificación urbana cognitiva; iii) diseño conceptual del sistema colaborativo de acceso a la vivienda y urbanismo (SCAVU); iv) recolección y análisis de la información en Quito y Portoviejo; y v) planteamiento de los escenarios de uso para la definición de los RFU en la construcción del prototipo. Los datos utilizados corresponden a la información provista por potenciales usuarios del aplicativo en talleres con instituciones públicas y gremiales, y a través de encuestas realizadas en espacios de encuentro ciudadano distribuidos en las dos ciudades antes mencionadas. Los RFU que describen las funciones particulares para el prototipo de software asumieron los hallazgos del análisis de la información recogida, evidenciándose que los escenarios de uso propuestos, vinculados a los RFU, han permitido al equipo de arquitectura cognitiva del proyecto avanzar con los requerimientos inteligentes del MPUC, los cuales han sido cristalizados en las primeras muestras del prototipo soportadas por el diseño de los algoritmos cognitivos.
\end{abstract}

\begin{abstract}
Considering the current housing situation, the weak participation in urban planning processes and the stagnation of the construction sector in Ecuador, the main objective of the Interuniversity Research Project "Cognitive Urban Planning" is the development of social web application that promotes collaborative urbanism within the framework of cognitive cities. This document seeks to establish the urban functional requirements (RFU) of the cognitive urban planning model (MPUC) for the development of a real-time collective work software prototype that allows access to housing and collaborative urbanism, as driving practices for a renewed urban planning in the Ecuadorian cities of Quito and Portoviejo. The research methodology is developed in five moments: i) Epistemological synthesis of the results of the systematic literature review (SLR); ii) review of a partial cognitive urban planning model; iii) conceptual design of the collaborative system for accessing to housing and urban planning (SCAVU); iv) collection and analysis of information in Quito and Portoviejo; and v) development of use cases for the definition of the RFU in the construction of the prototype. Potential users of the application provided the data during workshops with public institutions and unions, and through surveys conducted in community spaces in the two cities mentioned before. The RFUs that describe the functions for the software prototype assumed the findings of the analysis of the collected information. This evidenced that the
\end{abstract}

\footnotetext{
1 Doctor en Teoría Urbana por la Universidad Politécnica de Cataluña, Coordinador de Investigación del Máster en Ordenación del Territorio y Profesor de Planificación Urbana en la Universidad de Cuenca, http://orcid.org/0000-00017456-945X; ${ }^{2}$ Master en Planificación del Desarrollo Urbano por la University College of London, Director de Proyectos Urbanos de URLO Studio, https://orcid.org/0000-0002-2677-9679; ${ }^{3}$ Doctora en Tecnologías de la Información y las Comunicaciones por la Universidad Pompeu Fabra, Docente-Investigador del DICC en la Escuela Politécnica Nacional, https://orcid.org/0000-0002-4949-3278; ${ }^{4}$ Doctor en Ingeniería de Proyectos y Sistemas por la Universidad Politécnica de Cataluña, Investigador postdoctoral de la Universidad de Friburgo y Profesor en la Universidad Técnica de Manabí, https://orcid.org/0000-0002-8279-5630. * Correo de contacto: pedro.jimenezp@ucuenca.edu.ec
} 


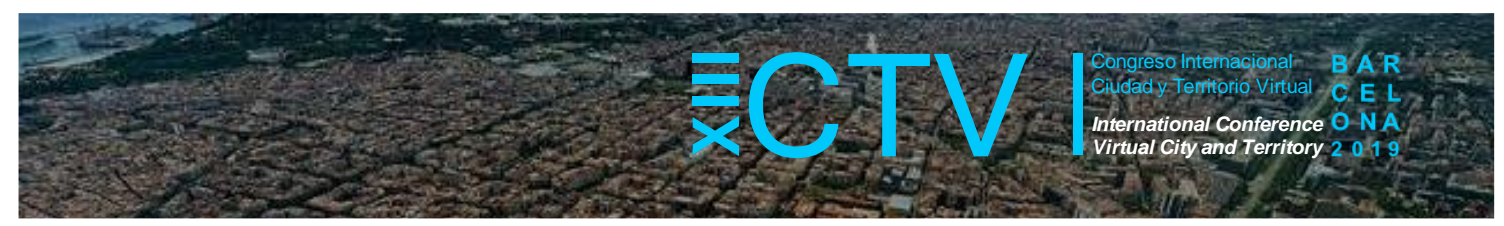

proposed use cases, linked to the RFU, allowed the project's cognitive architecture team to advance with the intelligent requirements of the MPUC, by elaborating the first prototype samples supported by cognitive algorithms design.

Palabras Clave: Planificación Urbana Colaborativa; Vivienda; Diseño de Prototipo de Software, Ciudades Cognitivas

Key words: Collaborative Urban Planning; Housing; Software Prototype Design; Cognitive Cities

\section{Introducción}

El $45 \%$ de los 3,8 millones de hogares ecuatorianos habitan en viviendas inadecuadas. Esta cifra contabiliza al $36 \%$ de hogares que sufren déficit cualitativo, y al $9 \%$ de los hogares que sufren déficits cuantitativos. De acuerdo con los datos proporcionados por el Ministerio de Desarrollo Urbano y Vivienda (MIDUVI), 1.37 millones de hogares con déficit cualitativo residen en viviendas cuya tenencia es insegura, construidas con materiales inadecuados, con carencia de servicios sanitarios básicos, o con problemas de hacinamiento; y 342.000 hogares con déficit cuantitativo comparten su vivienda con uno o más hogares, o viven en unidades de vivienda improvisadas (MIDUVI, 2015).

Mientras que en las áreas urbanas el $37 \%$ de los hogares habita en viviendas inadecuadas, este número llega al $60 \%$ en las zonas rurales. El mapa del déficit de vivienda del país repite el de la distribución de la población total, con el $80 \%$ de los hogares localizados en seis provincias: El Oro, Esmeraldas, Guayas, Los Ríos, Manabí y Pichincha². Siguiendo al MIDUVI, la causa principal del déficit de vivienda en Ecuador es la asequibilidad de la misma. Esto se explica por la disparidad entre ingresos de los hogares y los costos de la vivienda. Un hogar ecuatoriano promedio necesita ahorrar 41 sueldos mensuales para comprar una vivienda tipo ${ }^{3}$; para los hogares de los dos quintiles más pobres la brecha se amplía aún más, necesitando ahorrar 70 sueldos para acceder a una vivienda adecuada (UN-HABITAT, 2011). A pesar de los avances de los últimos 20 años, estos logros no han sido suficientes para responder al ritmo del crecimiento demográfico de Ecuador. Cada año, 111.000 hogares se suman a la población nacional, de los cuales más de la mitad se ubican en viviendas inadecuadas. El MIDUVI calcula que este crecimiento demográfico requiere agregar al mercado más de 64.000 viviendas nuevas por año.

Por otro lado, el sector de la construcción no consigue recuperarse tras una recesión de la economía nacional profundizada en los últimos 4 años. De acuerdo al Boletín Macroeconómico publicado por Asobanca (Enero, 2019), la actividad de la construcción ha estado correlacionada con el ciclo económico, ya que los trimestres en los que el PIB se ha ralentizado, la construcción ha guardado un comportamiento similar. En los últimos trimestres, esta realidad ha estado subordinada a la confluencia de varios factores, entre los que se destaca: incertidumbre, shocks negativos en el gasto de inversión del gobierno y baja estabilidad laboral (el empleo adecuado se encuentra estancado en niveles cercanos al $40 \%$ desde el primer trimestre de 2016). Luego de un periodo de crecimiento en que la construcción llegó a alcanzar tasas de aproximadamente el 20\% anual (2003 y 2012), se puede evidenciar una tendencia de desaceleración (crecimientos cada vez menores) entre el primer trimestre de 2012 y el primer trimestre de 2017, registrando tasas negativas en 2015, debido a un entorno macroeconómico desfavorable.

\footnotetext{
${ }^{2}$ Las ciudades de Quito y Portoviejo corresponden a las capitales provinciales de Pichincha y Manabí respectivamente.

3 Una vivienda tipo de interés social, de acuerdo al MIDUVI, está valorada en US\$22 mil, a la tasa de interés de mercado, a 30 años de plazo, y sin considerar la cuota inicial.
} 


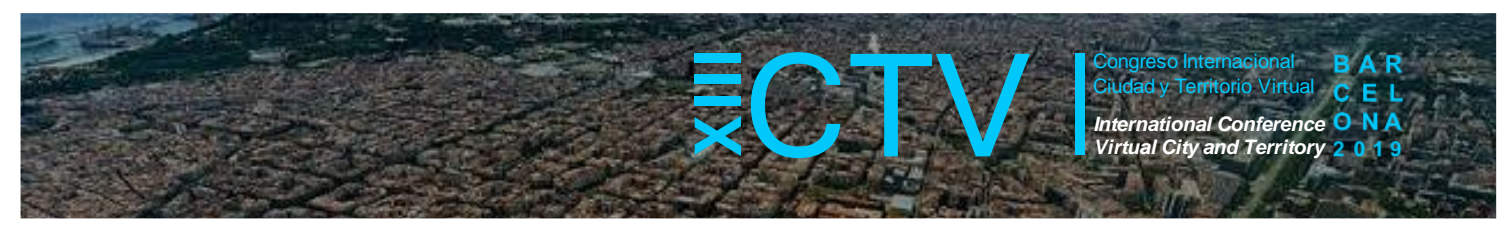

\subsection{Epistemología de la ciudad cognitiva: el reto de la planificación urbana y la vivienda}

En discusiones previas a la Conferencia Hábitat 3, uno de los desafíos más abrumadores evidenciados fue la provisión de vivienda adecuada y asequible, para lo cual se planteó, entre otros desafíos, el fortalecimiento del nexo entre vivienda y planificación urbana, considerándose fundamental la incorporación de procesos cooperativos en la planificación como catalizadores del acceso a la vivienda (UN-Hábitat, 2017). Las ciudades inteligentes bajo promesas de eficiencia y sostenibilidad no han conseguido responder hasta el momento a tales demandas de la ciudad futura (Finger \& Portmann, 2016). De este modo, utilizando los métodos científico y dialéctico se desarrolló una revisión sistemática de la literatura existente, lo que nos permite afirmar que la relación entre planificación urbana y vivienda en el marco de ciudades cognitivas aún se encuentra inconexa. Asimismo, al evaluar los resultados se evidenció una riqueza epistemológica dispersa, y una falta de horizonte teórico -en la evolución de los conceptos que llegan hasta las ciudades cognitivas- que relacione eficazmente la planificación urbana colaborativa con los retos de la vivienda en el marco propuesto; avalando así, la búsqueda de un cuerpo teórico que asegure sustento al desarrollo de un modelo de planificación urbana cognitiva.

El análisis permitió establecer el siguiente cuadro de resultados a modo de síntesis con el fin de evaluación de la SLR y discusión de los nuevos hallazgos:

- El peso predominante del enfoque teórico en el $100 \%$ de los documentos seleccionados garantizó la fiabilidad de la SLR al encontrarse la investigación en una fase epistemológica. Además, este enfoque presentó diferentes marcos conceptuales para cada caso, siendo preponderante el marco de ciudades inteligentes.

- Con relación a las posibilidades de contribución teórica de los estudios, se detectó la preponderancia de los aportes epistemológicos sobre los metodológicos, o sobre planteamientos teóricos más robustos. Sin embargo, esta riqueza de los conceptos acumulados en los últimos 40 años aún se muestra dispersa, respaldando nuestra intención de avanzar hacia un corpus teórico integrador.

- De la identificación de potenciales categorías teóricas en los estudios comparados, se expresaron con mayor importancia las relaciones a) Urban Planning-Cognition y b) Cognition-Social Behaviour. Así también, se destacó la transversalidad del tema de Gobernanza en la mayoría de investigaciones.

- Sobre el movimiento que han tomado las investigaciones en el tiempo, se puede destacar una clara dispersión de intereses. Precisamente, esta carencia de un horizonte común, reflexionado desde el urbanismo, ampara la búsqueda de un cuerpo teórico que de sustento a un futuro modelo de planificación urbana cognitiva.

- Finalmente, desde el punto de vista de una breve genealogía de la evolución del pensamiento sobre ciudades cognitivas, se muestran al menos tres autores que han forjado líneas de trabajo asociadas a la ciudad, pero con propósitos y enfoques distintos de la disciplina urbanística, y que han sido alimentados o seguidos por otros autores. Este es el caso de Juval Portugali, Allen Scott y Edy Portmann.

Debemos ser enfáticos en la importancia de Portmann y Finger (2016), quienes -siguiendo a Mostashari et al. (2011) que plantea por primera vez el concepto de ciudad cognitiva como un paradigma que aprovecha la tecnología de la información y la inteligencia artificial junto con la cognición humana para mejorar la toma de decisiones y la asignación de recursos en la 


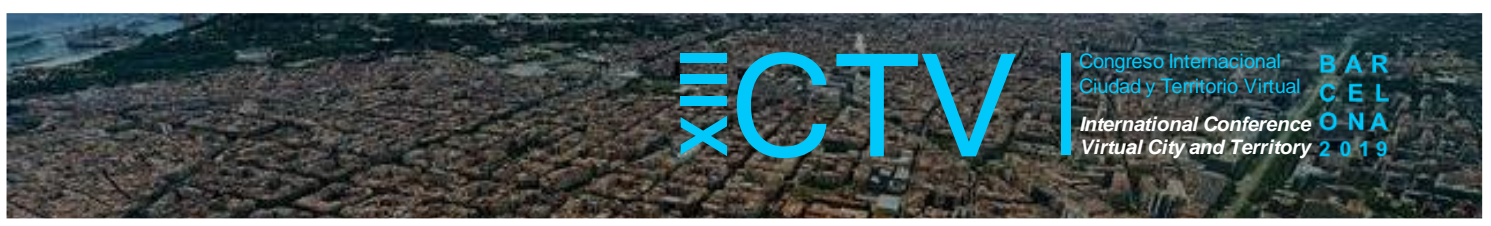

prestación de servicios urbanos ${ }^{4}$ - plantean que la ciudad inteligente (tecnocrática, eficientista) encuentra limitaciones para satisfacer los retos urbanos contemporáneos, lo cual les permite discutir el por qué las ciudades necesitan volverse cognitivas y, por tanto, por qué se necesita tal concepto. Así, proponen una ciudad basada en las ciudades del aprendizaje, que a su vez se enmarcan en la ciudad inteligente, complementándola. Su enfoque y argumentos se estructuran sobre tres desafíos actuales: la eficiencia, la sostenibilidad y la resiliencia, para intentar incidir en la evolución de los sistemas socio-técnicos urbanos (ver Tabla 1).

Tabla 1. Breve genealogía para ciudades cognitivas

\begin{tabular}{|c|c|c|c|}
\hline $\begin{array}{l}\text { Períodos } \\
\text { de interés }\end{array}$ & $\begin{array}{l}\text { Autores } \\
\text { principales }\end{array}$ & $\begin{array}{l}\text { Líneas de } \\
\text { investigación }\end{array}$ & Obras \\
\hline $1996-2016$ & $\begin{array}{l}\text { Juval } \\
\text { Portugali }\end{array}$ & $\begin{array}{l}\text { Brecha entre las intenciones y deseos de los } \\
\text { individuos y su comportamiento real. }\end{array}$ & $\begin{array}{l}\text { - (1996) The Construction of Cognitive Maps. } \\
\text { - (2000) Spatial Cognitive Dissonance and Socio-Spatial } \\
\text { Emergence in a Self-Organizing City. } \\
\text { - (2004) Toward a Cognitive Approach to Urban Dynamics. } \\
\text { - (2011) Complexity, Cognition and the City. } \\
\text { - (2016) Complexity, Cognition, Urban Planning and Design. }\end{array}$ \\
\hline $1997-2014$ & Allen Scott & $\begin{array}{l}\text { Nueva economía cognitivo-cultural ha sido la } \\
\text { causa principal del resurgimiento de las } \\
\text { principales ciudades de todo el mundo. }\end{array}$ & $\begin{array}{l}\text { - (1997) The Cultural Economy of Cities. } \\
\text { - (2006) Creative Cities: Conceptual issues and Policy Questions. } \\
\text { (2008) Social Economy of the Metropolis: Cognitive-Cultural } \\
\text { Capitalism and the Global Resurgence of Cities. } \\
\text { - (2014) Beyond the Creative City: Cognitive-Cultural Capitalism } \\
\text { and the New Urbanism. }\end{array}$ \\
\hline $\begin{array}{l}2016- \\
\text { actualidad }\end{array}$ & $\begin{array}{l}\text { Edy } \\
\text { Portmann }\end{array}$ & $\begin{array}{l}\text { Evolución de los sistemas urbanos relacionados } \\
\text { con la optimización de la visualización e } \\
\text { intercambio de datos con fines del aprendizaje } \\
\text { individual y colectivo, utilizando nuevas formas de } \\
\text { inteligencia de máquina que impliquen } \\
\text { interacciones hombre-máquina. }\end{array}$ & $\begin{array}{l}\text { - (2016) What Are Cognitive Cities? } \\
\text { - (2019) Designing Cognitive Cities }\end{array}$ \\
\hline
\end{tabular}

Fuente: Autores

De esta revisión inicial se considera que el uso de la SLR fue apropiado y consistente con la investigación, evidenciando que la relación entre planificación urbana y vivienda en el marco de las ciudades cognitivas obliga el tratamiento de múltiples disciplinas y enfoques. Este estudio es el primero de su tipo en el que se indaga sobre las ciudades cognitivas como marco para la articulación de la planificación urbana y la problemática de la vivienda, comprobando que el desarrollo de este tema es escaso, por no decir inexistente. En este sentido, damos un primer paso en la construcción de un marco epistemológico plural que sirva de base para el diseño de un modelo de planificación urbana cognitiva con aplicativo en la vivienda.

\section{Un modelo parcial de planificación urbana cognitiva}

Siguiendo la línea de ciudad cognitiva propuesta por Portmann y Finger (2016), Meza et al. (2019) plantea un marco de referencia para que la comunidad científica y la industria puedan descubrir el potencial de la inteligencia colectiva (IC), los sistemas de información geográfica (SIG) y los sistemas cognitivos (SC) como modos de abordar el problema de la urbanización en la ciudad. Así, su trabajo explora el impacto de la IC, los SIG y los SC como una forma de apoyar la toma de decisiones de los gobiernos municipales, para enfrentar los desafíos anunciados por la ONU en la Nueva Agenda Urbana 2017 en materia de acceso a la vivienda; validando la influencia de IC, SIG y CS en los procesos de toma de decisiones de todos los actores en un proceso innovador de planificación urbana.

\footnotetext{
${ }^{4}$ Mostashari et al. (2011) explica que una ciudad cognitiva es aquella que aprende y adapta su comportamiento basado en experiencias pasadas y es capaz de sentir, comprender y responder a los cambios en su entorno.
} 


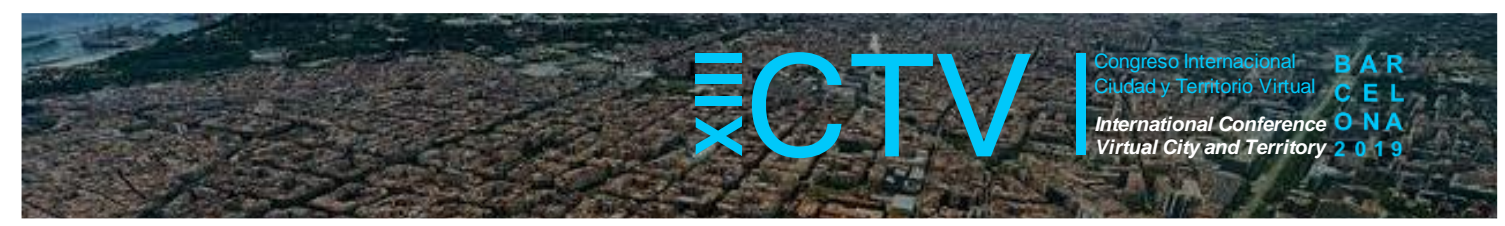

\subsection{La ciudad cognitiva}

Para avanzar en la construcción del modelo teórico se busca sintetizar los conceptos articulados por Meza et al. (2019) en el camino hacia un modelo de planificación urbana colaborativa y su impacto en el desarrollo de la ciudad cognitiva. Los autores parten de plantear que una ciudad inteligente sociable permitiría una transformación de la sociedad en un dominio más participativo, considerando que tal situación podría mejorar el proceso de toma de decisiones en la planificación urbana, así como la concienciación y participación de los ciudadanos en el contexto de las ciudades cognitivas.

En esta dirección, siguiendo su argumentación, un plan cognitivo podría aplicarse en 1) ayudar a los ciudadanos a seleccionar mejor sus casas de acuerdo con sus perfiles individuales, brindando consejos y recomendaciones en tiempo real sobre la situación urbanística y la vivienda; 2) apoyar el proceso de toma de decisiones de las instituciones gubernamentales de manera que promuevan la planificación urbana inclusiva; y 3) promover la concientización de las partes interesadas sobre el impacto de la IC en el proceso de planificación urbana. Así, en las consideraciones de Meza et al. (2019) las ciudades actualmente estarían creciendo dentro de las tecnologías, impulsando a la planificación urbana hacia su integración con las TIC, obteniendo beneficios prácticos para la comunidad.

Coincidiendo con los autores, la planificación urbana colaborativa requiere de procesos cognitivos (mentales) que incluyan las decisiones individuales y/o colectivas, la resolución de problemas y el aprendizaje, pero también los comportamientos y las relaciones en el entorno en que se toman las decisiones (por ejemplo: en el marco del sistema inmobiliario). De allí, que estos procedimientos según Thagard (2016) tienen un importante componente emocional: el factor humano cognitivo, expresado en los siguientes aspectos de la planificación urbana:

a. Los valores mentales (es decir, representaciones emocionales y mentales de cosas y situaciones) demandados en la planificación urbana;

b. la coherencia emocional respaldada por las decisiones de diseño en las ciudades;

c. una planificación urbana contemporánea abierta a nuevos indicadores semánticos que atiendan a un tipo de representación neuronal;

d. la capacidad de los sistemas multi-agente (los agentes también son emocionales) de modelar los procesos sociales de la planificación urbana;

e. la complejidad de los mecanismos que emergen del desarrollo urbano que producen niveles de incertidumbre; $y$

f. la comprensión de los procesos sociales y cognitivos en apoyo a la transformación de las personas en fuentes de creatividad, y a las ciudades en obras colectivas.

\subsection{Conectivismo para la gobernanza cognitiva}

Como se explicó anteriormente, una ciudad cognitiva es un paradigma que capitaliza la tecnología de la información y la inteligencia artificial, junto con la cognición humana, para mejorar la toma de decisiones con respecto a los servicios urbanos y la distribución de recursos. En tanto que es una ciudad aprende y ajusta su funcionamiento sobre la base de experiencias pasadas, comprendiendo y respondiendo a las alteraciones en sus condiciones de funcionamiento, el modelo parcial internaliza una relación profunda con el aprendizaje.

Mostashari et al. (2011) explica que para alcanzar una gobernanza cognitiva, es necesario obtener una variedad de parámetros de rendimiento para cada sistema de infraestructura, que 


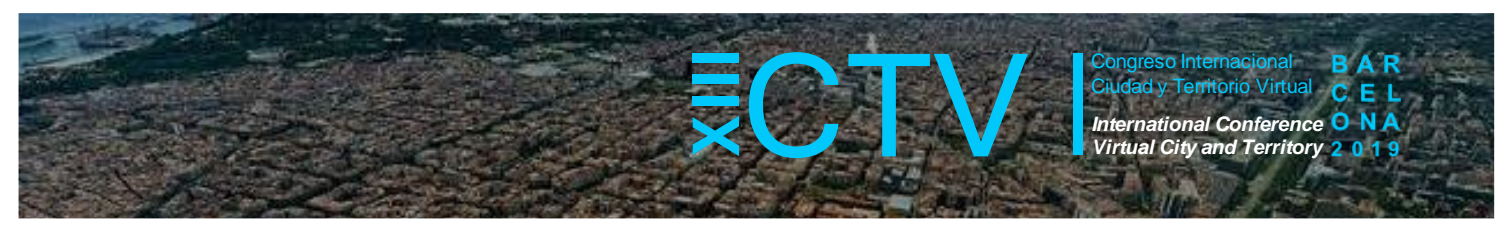

reconozcan las aspiraciones de los diversos interesados dentro del contexto urbano. Estos parámetros de rendimiento urbano sirven, a su vez, para evaluar el estado de los servicios en territorio a corto, mediano y largo plazo. Para factores en tiempo real o a corto plazo, el enfoque de estos parámetros busca identificar resoluciones rápidas a situaciones. Mientras tanto, a mediano y largo plazo, su atención se centra en la mejora constante de la calidad de vida de los ciudadanos, sin descuidar los valores ambientales del entorno.

En todo el mundo, las teorías de aprendizaje más utilizadas para la creación de escenarios de instrucción son el conductismo, el cognitivismo y el constructivismo. Sin embargo, es importante enfatizar que todos ellos fueron desarrollados cuando el aprendizaje y la enseñanza no eran influenciados por la tecnología, y por tanto presentan limitaciones. El factor principal de la mayoría de las teorías de aprendizaje es que el aprendizaje ocurre en una persona; estos postulados no abordan el aprendizaje que se produce sin o fuera de las personas y tampoco describen cómo se produce el aprendizaje dentro de las organizaciones.

Así, en la era digital, ha surgido una nueva teoría denominada "conectivismo". Esto se refiere a la integración de los principios explorados por el caos, la red, la complejidad y las teorías de autoorganización. Aquí, el aprendizaje es un proceso que ocurre dentro de entornos de elementos centrales cambiantes, que no están completamente bajo el control de los individuos. En este sentido, el aprendizaje puede generarse sin personas y se basa en conjuntos de información de conexión especializada.

El conectivismo parte del entendimiento de que las decisiones se basan en fundaciones que se alteran rápidamente, debido a la información novedosa que se adquiere continuamente. Según Siemens (2005), los principios del conectivismo pueden resumirse en que el aprendizaje y el conocimiento se basan en una diversidad de opiniones y que la toma de decisiones es en sí misma un proceso de aprendizaje, de ese modo, "elegir qué aprender o el significado de la información de ingreso pasa a través del lente de una realidad cambiante...si bien ahora hay una respuesta correcta, puede ser incorrecta mañana debido a alteraciones en el clima de información que afectan la decisión" (Siemens, 2005:7).

\subsection{La planificación en el proceso cognitivista}

A partir de estas consideraciones, Mostashari et al. (2011) establece un modelo de dos etapas dedicadas a la arquitectura y al proceso cognitivos. Las cuales consideran los niveles de organización tácticos y operativos; pero es necesario insertar el proceso de planificación cognitiva, que siguiendo a Thagard (2016) debe posicionarse dentro del nivel estratégico de la organización, en tanto que requiere muchas habilidades relacionadas con la creatividad, así como el uso de la mayoría de los tipos de inteligencia disponibles en los seres humanos.

Tabla 2. Organización de fases cognitivas

\begin{tabular}{ccc} 
& Fases Cognitivas & Nivel de Organización \\
\hline 1 & Planificación & Estratégico \\
2 & Arquitectura & Táctico \\
3 & Procesos & Operativo \\
\hline
\end{tabular}

Fuente: Autores.

En la Figura 1 se define cada una de las tres fases con sus procedimientos asignados de acuerdo con el enfoque del proceso cognitivista descrito en Meza et al (2019). 


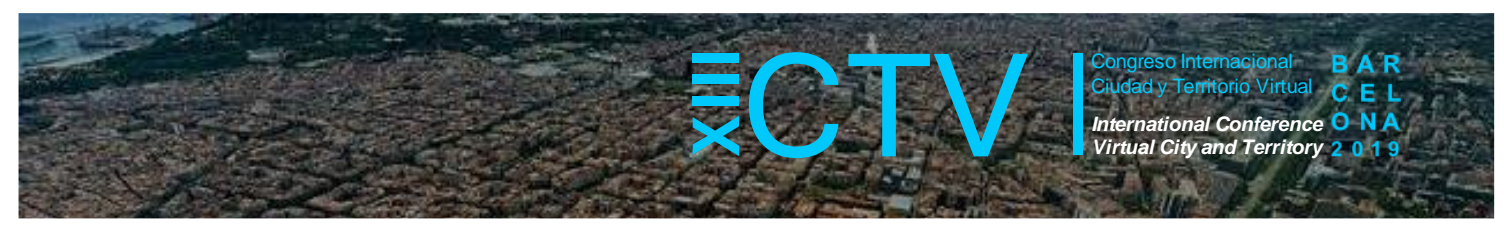

Figura 1. Fases cognitivas para la gobernanza urbana

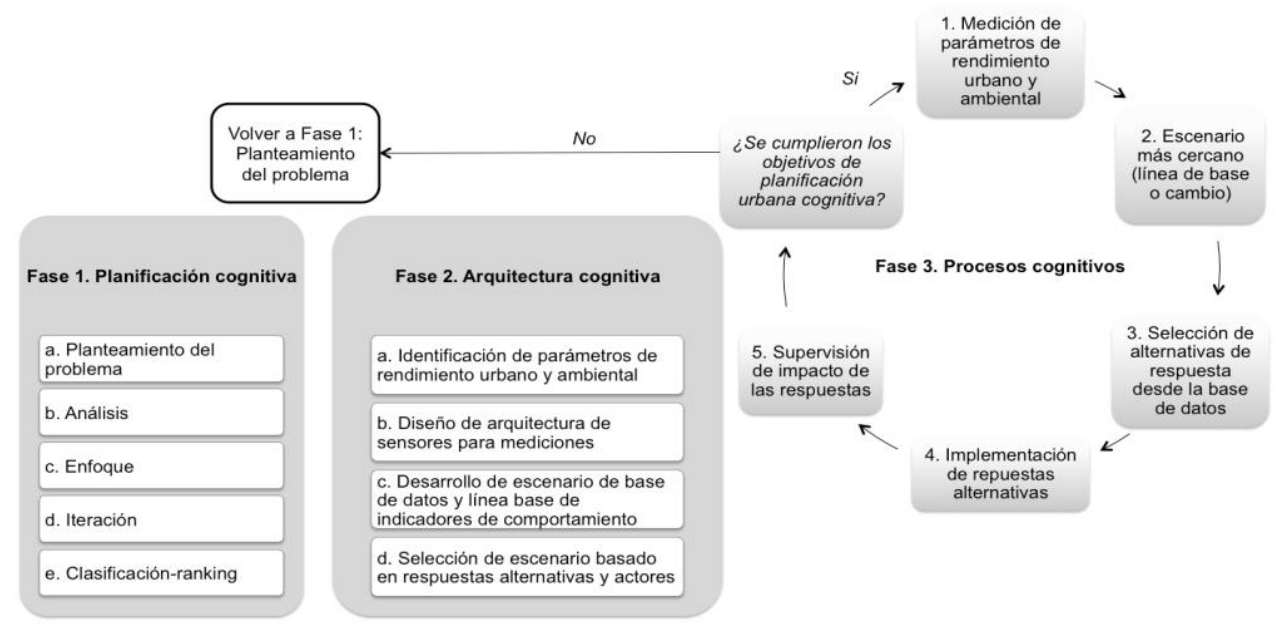

Fuente: Meza et al. (2019).

Como se mencionó en párrafos anteriores, las técnicas de inteligencia artificial ya no tienen la tarea de resolver el proceso de planificación estratégica por sí mismas. De esta manera, este modelo parcial combina humanos y máquinas para aumentar la efectividad de la planificación urbana colaborativa. En este camino hacia un modelo de planificación urbana cognitiva, Meza et al. (2019) buscan dar coherencia al proceso de fases cognitivas incluyendo a los actores en relación con los grupos de técnicas de cooperación utilizadas en la planificación urbana colaborativa, y los grupos de herramientas de inteligencia artificial que respaldan cada fase y actor. Así pues, enfatizan que el éxito de la planificación urbana colaborativa en entornos cognitivos requiere una interfaz hombre-máquina para lograr los mejores resultados en el uso de paradigmas de inteligencia colectiva.

Siguiendo el enfoque de la planificación urbana colaborativa, Meza et al. (2019) establece para su modelo parcial tres actores principales: 1) los ciudadanos, que pueden ser humanos 0 sensores inteligentes; 2) el personal directivo, que corresponde al equipo ejecutivo de alto nivel de la organización gubernamental que administra el plan; y 3) los técnicos, cuyos deberes recaen en el equipo responsable de las tareas tácticas del gobierno, generalmente compuesto por arquitectos, urbanistas, ingenieros y geógrafos, así como especialistas en telecomunicaciones y sistemas, entre otros. A partir de aquí, es necesario centrarnos en la Fase 1 (Planificación cognitiva) del modelo inicial para posteriormente acoplar en esta etapa el diseño de un sistema colaborativo de acceso a la vivienda y urbanismo que permita definir el cuadro de actores, su relacionamiento y roles.

\subsection{Planificación cognitiva}

Esta fase fue agregada en Mesa et al. (2019) como un elemento faltante al proceso presentado en Mostashari et al. (2011), en tanto que la planificación utiliza el más alto nivel de cognición humana, aún desamparado por los sistemas inteligentes, y en el que los seres humanos son el elemento transversal, y el sistema inteligente es un apoyo para la toma de decisiones en procesos colaborativos de planificación urbana. Esta etapa se completa en cinco pasos que permiten establecer el desarrollo de la planificación utilizando los paradigmas del urbanismo colaborativo. Estos procesos se pueden facilitar dentro del entorno de un plan estratégico urbano de una oficina municipal competente. El cuadro de actores preliminar es el siguiente: 


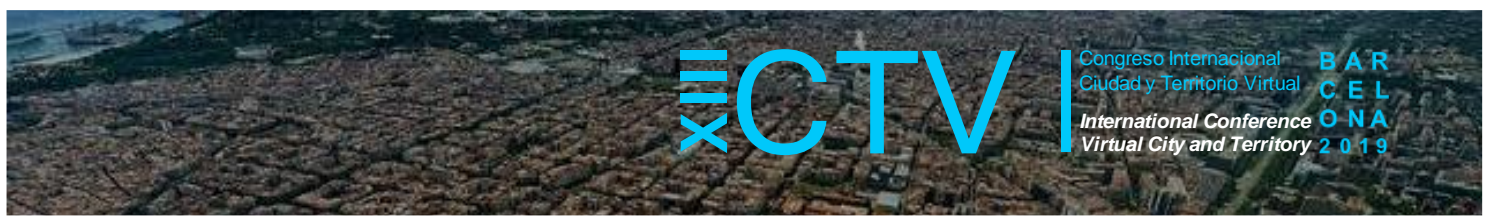

a. Los Ciudadanos.- se requieren técnicas de recolección de datos que permitan a los ciudadanos evaluar y resolver el problema. Mantener una retroalimentación constante permite capturar la realidad específica de la óptica de los ciudadanos. En apoyo de este proceso, se recomienda al usuario de herramientas tecnológicas capturar las emociones de los ciudadanos a través de interfaces hombre-máquina que simulen escenarios interactivos naturales (es decir, imágenes dinámicas y 3D). Finalmente, para la determinación de patrones y la toma de decisiones, el análisis de datos en tiempo real constituye una solución integral.

b. El Personal.- es indispensable un proceso de toma de decisiones que determine la certeza del problema por parte de los niveles directivos de las organizaciones gubernamentales. Este proceso podrá confiar en los mecanismos de información de los residentes en las bases de datos históricas (estructura de conocimiento), así como en el análisis estadístico de los datos proporcionados por los ciudadanos (datos inteligentes).

c. Los Técnicos.- la información recopilada por diferentes medios debe ser analizada y sintetizada por el equipo de especialistas en el proceso de planificación cognitiva. Además, la planificación urbana colaborativa requiere una devolución creativa de la información que permita que los acuerdos lleguen a todos los participantes. En este contexto, se requieren técnicas de participación cognitivas que recojan la información histórica y permitan el análisis colectivo de datos estructurados y no estructurados en tiempo real.

Figura 2. Proceso de planificación cognitiva

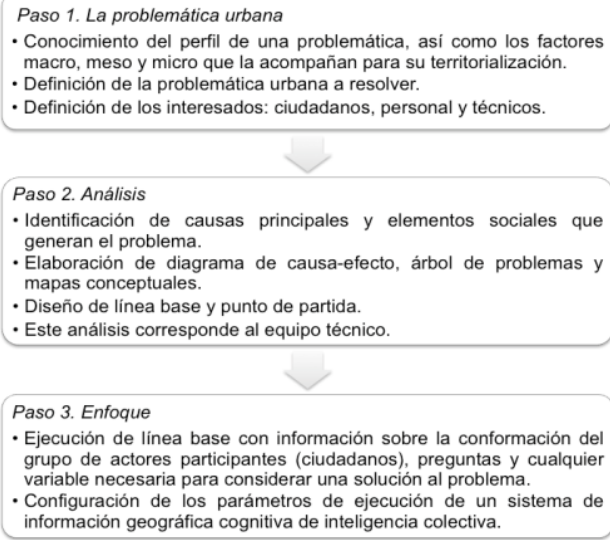

Fuente: Meza et al. (2019).

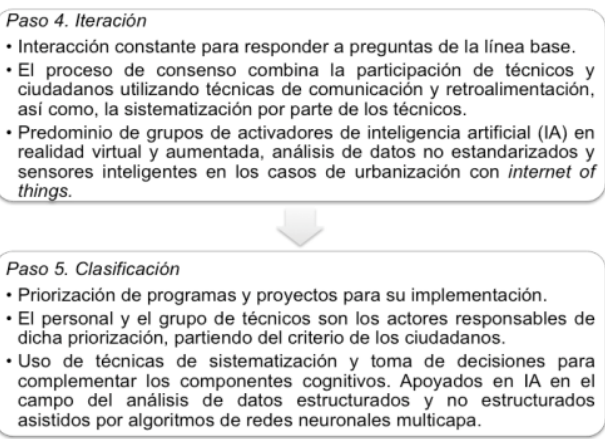

A partir del modelo parcial presentado (de máxima abstracción en el campo del desarrollo urbano) se pretende definir una estructura conceptual del MPUC, que incorpore los resultados de la síntesis epistemológica y las teorías abordadas, en dirección hacia el acceso a la vivienda y el urbanismo colaborativos.

\section{Diseño de un sistema colaborativo de acceso a la vivienda y urbanismo}

Habiendo delineado el proceso cognitivista con su fase de planificación, nuestro modelo de planificación urbana cognitiva asume un procedimiento esencial que implica ir más allá del concepto cuantitativo y cualitativo de necesidad básica de un grupo poblacional, hacia la comprensión de los deseos y el comportamiento del usuario en relación con su entorno, y de su creatividad dentro de una economía cognitiva-cultural. En este sentido, sabemos que bajo el sistema convencional de acceso a la vivienda se conseguiría cubrir potencialmente las 


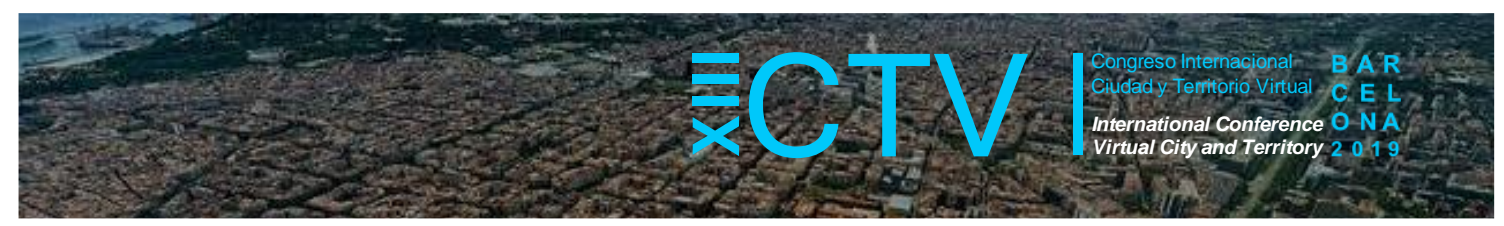

necesidades (mínimas) insatisfechas; sin embargo, estas necesidades están normalmente mediadas por agentes públicos y fundamentalmente privados, que en la práctica -siguiendo a Portugali (2000)- terminan direccionando o restringiendo el comportamiento real de la población. Entonces, el propósito teórico de este modelo de planificación urbana cognitiva es que los deseos de los usuarios que demandan una solución habitacional se cumplan al $100 \%$ bajo nuevas reglas de cooperación entre actores integrados a un sistema colaborativo de acceso a la vivienda y urbanismo (SCAVU). En consecuencia, si lográsemos satisfacer un porcentaje amplio de las aspiraciones del usuario que encuentra una solución habitacional contribuiríamos directamente al aumento del bienestar subjetivo y la calidad de vida de ese segmento de la población, sumado al bienestar colectivo del vecindario de acogida.

Siguiendo las pautas del modelo parcial desarrollado por Meza et al. (2019), consideramos que lo anterior tendría una traducción en el incremento de la eficiencia urbana desde dos enfoques: i) enfoque de la gobernanza.- en la gestión de la infraestructura y los servicios urbanos, la optimización de los subsidios y la tributación, la planificación colaborativa de la urbanización y la regulación del uso del suelo; y ii) enfoque de innovación social.- mediante la optimización de recursos financieros para los usuarios, ahorro de tiempo y transparencia en la información, por tanto, mayor comunicación y apropiación vecinal.

Tabla 3. Diseño conceptual del SCAVU

\begin{tabular}{|c|c|c|}
\hline $\begin{array}{l}\text { Categoría de } \\
\text { Usuarios }\end{array}$ & $\begin{array}{c}\text { Actores y posibles interesados en Quito y } \\
\text { Portoviejo }\end{array}$ & ¿Qué se espera? \\
\hline $\begin{array}{l}\text { Población que } \\
\text { desea una } \\
\text { solución } \\
\text { habitacional }\end{array}$ & $\begin{array}{l}\text { - Usuarios que desean comprar, alquilar, edificar o } \\
\text { mejorar una vivienda. }\end{array}$ & $\begin{array}{l}\text { - Que expresen sus deseos sin restricciones; } \\
\text { - que sea transparente con la información que proporciona; y } \\
\text { que adquiera conciencia de su importancia en el SCAVU. }\end{array}$ \\
\hline $\begin{array}{l}\text { Operadores } \\
\text { institucionales }\end{array}$ & $\begin{array}{l}\text { - Unidades de planificación urbana, políticas } \\
\text { territoriales, vivienda y avalúos del GAD Municipal } \\
\text { Portoviejo y del MDMQ. } \\
\text { - Organizaciones sociales por la vivienda y/o Academia } \\
\text { (Facultades de Arquitectura o escuelas de } \\
\text { urbanismo). }\end{array}$ & $\begin{array}{l}\text { - Que las unidades de planificación y política urbana administren el SCAVU } \\
\text { de acuerdo a sus competencias; } \\
\text { - que las unidades de vivienda adapten sus programas a los deseos de los } \\
\text { usuarios, y optimicen los incentivos e impuestos; } \\
\text { - que las unidades de avalúos actualicen los valores del suelo; } \\
\text { - que se conformen veedurías institucionales. }\end{array}$ \\
\hline $\begin{array}{l}\text { Sector } \\
\text { inmobiliario } \\
\text { que provee } \\
\text { una solución } \\
\text { habitacional }\end{array}$ & $\begin{array}{l}\text { - Pequeños propietarios (oferta espontánea de venta o } \\
\text { alquiler de vivienda). } \\
\text { - Promotores/Desarrolladores inmobiliarios (oferta } \\
\text { estudiada de venta o alquiler de vivienda). } \\
\text { - Constructores menores (arquitectos y técnicos de } \\
\text { construcción). }\end{array}$ & $\begin{array}{l}\text { - Que pequeños propietarios puedan vender o alquilar la vivienda con } \\
\text { agilidad y ahorro de recursos, sin intermediarios; } \\
\text { - que los promotores contribuyan en la oferta de vivienda con pertinencia; } \\
\text { - que los profesionales de la construcción accedan a los requerimientos de la } \\
\text { demanda de edificación y mejora de vivienda. }\end{array}$ \\
\hline $\begin{array}{l}\text { Población de } \\
\text { acogida }\end{array}$ & $\begin{array}{l}\text { - Vecinos voluntarios de acogida a nuevos residentes } \\
\text { en la comunidad. } \\
\text { - Asociaciones de vecinos u organizaciones barriales. }\end{array}$ & $\begin{array}{l}\text { - Que la población voluntaria de la comunidad de acogida se convierta en } \\
\text { intermediario de la transacción; } \\
\text { - que las organizaciones barriales interactúen con el nuevo vecino. }\end{array}$ \\
\hline
\end{tabular}

Fuente: Autores.

De este modo, el diseño del SCAVU propone cuatro categorías de usuarios dispuestos en orden jerárquico, siendo los usuarios en busca de una solución habitacional los que mayor jerarquía tienen en este sistema. Así, el MPUC se plantea como desafío que cada una de las partes interesadas gane algo, cooperando, para que estos usuarios hagan posibles sus deseos ya no solo de acceso a la vivienda, sino respecto del habitar en comunidad en términos amplios. A continuación, se delimitan las categorías de usuarios del SCAVU y lo que se espera de cada una de ellas, con el objetivo de proporcionar elementos clave y variables potenciales para la recolección de información.

Así, el modelo teórico tiende a traspasar el control del acceso a la vivienda del sector inmobiliario convencional (conducido por el sistema de promoción: inversores, grandes propietarios y promotores) al operador institucional, que tiene la obligación de velar por los intereses del usuario a través de sus competencias en: planificación de la urbanización, control y regulación del uso del suelo; así como, promoción del acceso a la vivienda entendida como 


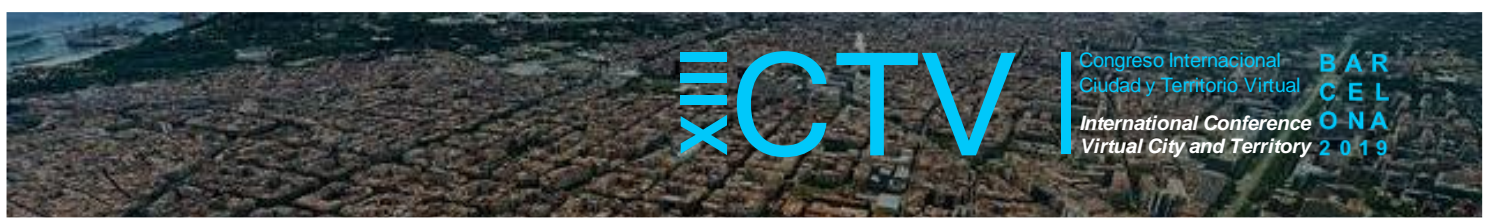

derecho fundamental, mas no como mercancía; y en fomento del empleo. En esta dirección, se busca prescindir de los intermediarios (corredores de bienes raíces y plataformas publicitarias inmobiliarias) que encarecen el precio final de transacción, reemplazándolos por un aplicativo (software) de confianza y por actores voluntarios en barrios de acogida.

\section{Encuestas en las ciudades de Quito y Portoviejo}

El diseño de la encuesta recogió información de los deseos de la gente respecto de la vivienda, de las condiciones de habitabilidad y del entorno anheladas en una muestra de residentes de la población económicamente activa (personas entre 25 a 60 años) de Quito y Portoviejo ${ }^{5}$. La encuesta se realizó de modo presencial en espacios de encuentro ciudadano (parques, centros comerciales, etc.) distribuidos estratégicamente en las dos ciudades. Se entrevistó a 1.848 personas en Quito y 1.838 en Portoviejo.

\section{Tabla 4. Factor humano cognitivo en diseño de encuestas}

\begin{tabular}{|c|c|}
\hline $\begin{array}{l}\text { Perfiles } \\
\text { seleccionados }\end{array}$ & formación que busca recopilar la encuesta \\
\hline $\begin{array}{l}\text { Usuario que } \\
\text { desea una } \\
\text { solución } \\
\text { habitacional }\end{array}$ & $\begin{array}{l}\text { - Satisfacción general con respecto al lugar de residencia y de la vivienda. } \\
\text { Motivos que impulsan el deseo de mudanza o arraigo al barrio de residencia. } \\
\text { - Aspiraciones de reformas o adecuaciones de vivienda. } \\
\text { - Expectativa de oferta de servicios por parte de profesionales de la construcción. } \\
\text { - Razectativa de intervenciones municipales en el barrio. } \\
\text { - Aspiraciones condiciones que justifiquen las preferencias de construir, comprar o alquilar una vivienda frente a otras opciones. } \\
\text { - Aspiraciones de tipología de vivienda. }\end{array}$ \\
\hline Vecino & $\begin{array}{l}\text { Voluntad de participar en el desarrollo urbano y apropiación por el barrio. } \\
\text { - Voluntad de establecer lazos comunitarios y capacidad de acción para asistir a nuevos residentes (acogida en el barrio). }\end{array}$ \\
\hline $\begin{array}{l}\text { Pequeño } \\
\text { propietario }\end{array}$ & $\begin{array}{l}\text { - Razones y/a condiciones que justifican alquilar o vender una vivienda. } \\
\text { - Medios utilizados para ofertar el inmueble. } \\
\text { - Método utilizado para determinar el precio de alquiler o venta. } \\
\text { - Actor encargado de la intermediación en campo para mostrar el inmueble. }\end{array}$ \\
\hline $\begin{array}{l}\text { Pequeño } \\
\text { constructor }\end{array}$ & $\begin{array}{l}\text { - Razones y/a condiciones que dificultan el hallazgo de usuarios que demandan una vivienda. } \\
\text { - Razones que impiden a los constructores ofertar sus servicios. } \\
\text { - Relación del sector de la construcción con actores del sistema inmobiliario. } \\
\text { - Exticulación con la estructura de planificación urbana municipal. } \\
\text { - Expectativas acerca de la relación entre actores del sistema inmobiliario para mejorar el acceso a la vivienda. }\end{array}$ \\
\hline
\end{tabular}

Fuente: Autores.

De acuerdo a los posibles actores previstos en el SCAVU, el equipo de investigación decidió seleccionar cuatro perfiles esenciales para el diseño de la encuesta: i) aquellos que demandan una solución habitacional; ii) personas que no requieren una vivienda y solo se consideran vecinos; iii) propietarios de una vivienda que está en venta y/o arriendo; y iv) profesionales de la construcción. Asociados a estos perfiles se planteó un número específico de preguntas; de tal modo, la encuesta consistió en 65 preguntas abiertas, doce de las cuáles son preguntas generales para todos los participantes, y entre 4 y 11 preguntas específicas dependiendo del perfil del encuestado. Las preguntas específicas fueron no estructuradas para permitir al encuestado desarrollar sus aspiraciones, evitando las limitaciones de categorías de respuesta predefinidas (Cohen et al., 2007). Las generales recogieron información de la persona, en concreto los datos de: edad, género, profesión, número de miembros del hogar, ingresos y gastos mensuales; mientras que las específicas asociadas a cada perfil recopilaron la información del factor humano cognitivo conforme a la Tabla 4.

Los resultados han sido clasificados en cuatro tipos: i) resultados generales de población encuestada; ii) resultados de validación del SCAVU (ver Tabla 4); iii) resultados de caracterización de perfiles del usuario; y iv) resultados de comparación para el caso de Quito y

\footnotetext{
${ }^{5}$ De acuerdo al método de diseño del tamaño óptimo de la muestra se obtuvo una fiabilidad de los resultados del $99 \%$ en ambas ciudades.
} 


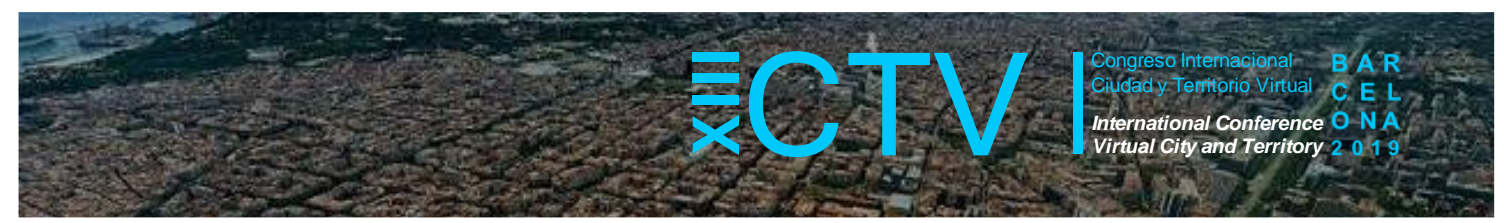

Portoviejo. Los resultados tipo (i) indican que la muestra está balanceada en términos de género con una mayoría de hombres alrededor del $52 \%$ versus $48 \%$ de mujeres. El $71,85 \%$ de las personas en Quito y $61,70 \%$ en Portoviejo tiene ingresos familiares de hasta USD 1.000 , y la mayoría demandan una solución habitacional o se consideran "vecinos" $(79,51 \%$ en Quito y $83,90 \%$ en Portoviejo). Por otro lado, de entre los usuarios que requieren una solución habitacional, alrededor del $38,5 \%$ desean hacer mejoras en sus viviendas, seguidas por quienes quieren construir o comprar. Por último, la mayoría de las personas encuestadas están conformes con su lugar de residencia y busca que sus barrios sean seguros, cuenten con servicios básicos, equipamientos, espacios públicos de calidad, y con una buena ubicación en la ciudad.

Los resultados tipo (ii) respaldaron las premisas respecto de los posibles actores planteados en Tabla 3. Por ejemplo, se confirmó en ambas ciudades que los vecinos tienen la voluntad de asistir a nuevos residentes: $84,02 \%$ en Quito y $81,15 \%$ en Portoviejo.

\section{Tabla 5. Resultados tipo (ii) de validación del SCAVU}

Actores en Quito y Portoviejo

Usuarios que desean comprar, alquilar, edificar o mejorar una vivienda (demanda).

Validación del SCAVU

Sólo el 13,93\% de los encuestados en Quito y el 10,53\% en Portoviejo no están conformes con su lugar de residencia. Las personas buscan que sus barrios sean seguros, tranquilos, que cuenten con servicios básicos, áreas verdes, espacios públicos, que sea limpio, y que sea céntrico y servido de infraestructura y equipamientos, entre otros.

Pequeños propietarios (oferta espontánea).

La mayoría de los propietarios alquilan o venden su vivienda para generar mayores ingresos $(25,19 \%)$ o por una necesidad económica $(21,76 \%)$. Le siguen aquellos que buscan tener una mejor vivienda o que sea propia. La mayoría de los propietarios ofertaron sus viviendas por medio de internet $(31,01 \%)$, redes sociales $(15,12 \%)$, anuncios $(13,57 \%)$, y promotoras inmobiliarias $(6,20 \%)$.

Alrededor del $31 \%$ de los propietarios publicitan su vivienda en internet, seguido por redes sociales $(15,12 \%$ en Quito y $20,78 \%$ en Portoviejo) y anuncios en medios físicos (13,57\% en Quito y $14,29 \%$ en Portoviejo).

Promotores inmobiliarios (oferta estudiada).

Entre los problemas que los constructores tienen para ofertar sus servicios consta la falta de publicidad $(9,68 \%$ en Quito y $4,76 \%$ en Portoviejo), la falta de una relación con las promotoras inmobiliarias $(53,13 \%$ en Quito y $40,48 \%$ en Portoviejo), y no tener una relación con los corredores de bienes raíces y las plataformas de publicidad (68,75\% en Quito y $33,33 \%$ en Portoviejo)

Constructores (profesionales y Entre los problemas de los constructores para acceder a la demanda de vivienda constan la falta de información técnicos de construcción). del mercado inmobiliario $(3,13 \%$ en Quito y $4,76 \%$ en Portoviejo), los altos costos de construcción $(6,25 \%$ en Quito y $7,14 \%$ en Portoviejo), y la situación económica desfavorable del país $(9,38 \%$ en Quito y $2,38 \%$ en Quito y $7,14 \%$

Otros problemas que los constructores tienen para ofertar sus servicios son la ubicación no preferida, el alto costo del suelo deseado disponible (12,90\% en Quito y $7,14 \%$ en Portoviejo), y la falta de infraestructura adecuada (6,45\% en Quito y $16,67 \%$ en Portoviejo).

$55,88 \%$ de constructores en Quito y 73,13\% en Portoviejo tienen una relación con las promotoras e inversores inmobiliarios.

$58,88 \%$ de constructores en Quito y $71,64 \%$ en Portoviejo tienen una relación con los corredores de bienes raíces y las plataformas de publicidad.

Vecinos voluntarios de barrios de $\quad 84,02 \%$ de los vecinos de acogida en Quito y $81,15 \%$ en Portoviejo están dispuestos a colaborar con los nuevos acogida a nuevos residentes. $\quad$ residentes.

Fuente: Autores.

Los resultados tipo (iii) indican con respecto al usuario que demanda una solución habitacional, que la mayoría son jóvenes de hasta 39 años, 68\% para Quito y 72\% para Portoviejo. El 71\% y $68 \%$ de las personas tiene ingresos de hasta USD 1.000 en Quito y Portoviejo, respectivamente; mientras que para el $90 \%$ y $82 \%$, sus gastos son de hasta USD 1.000. Así, se evidencia que este perfil de usuario reporta un mayor nivel de gastos que ingresos. Además, se hace una caracterización de cuatro perfiles de usuarios dentro de esta categoría, es decir, de aquellas personas que desean mejorar, construir, comprar o arrendar una vivienda, todas ellas con resultados similares a los descritos en este perfil.

Respecto del perfil de propietario, la mayoría de encuestados tiene entre 30 y 39 años, con ingresos entre USD 601-1.000 en Quito y Portoviejo, y gastos que varían entre el salario básico y USD 600 para Quito, y menores al salario básico en Portoviejo. El 26,34\% y 40,79\% de estos propietarios, desean vender o arrendar su inmueble respectivamente, para generar ingresos adicionales, seguidos por alrededor de un $22 \%$ en ambas ciudades que lo hacen porque tienen 


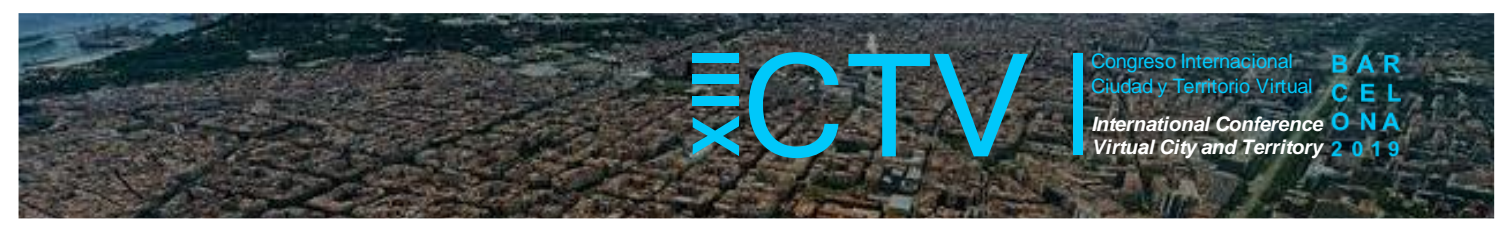

una necesidad económica. Asimismo, los medios más utilizados en las dos ciudades para publicitar la vivienda son el internet, con un $31 \%$, y las redes sociales con un $18 \%$.

En relación a los constructores, se observa que $68 \%$ y 72 \% son relativamente jóvenes de hasta 39 años, con ingresos entre USD 394 y USD 1.000 para Quito (68\%) y entre USD 1.001 y USD 3.000 para Portoviejo (49\%), mientras que la mayoría tiene gastos entre el salario mínimo y USD 600 en Quito, y entre USD 601 y USD 1.000 en Portoviejo. Además, se precisa que entre los problemas para acceder a la demanda de vivienda constan: el acceso a financiamiento, los altos costos de construcción, la difícil situación económica del país, y la complejidad de los permisos y normativa. En cuanto a los problemas para ofertar sus servicios, se presentan la ubicación y precio del suelo, la falta de publicidad de sus proyectos y la inadecuada infraestructura y servicios urbanos existentes alrededor de los mismos. Por último, la mayoría de los constructores dice no tener una relación con las promotoras inmobiliarias, corredores de bienes raíces o plataformas de publicidad.

En cuanto a los identificados como vecinos, tienen entre 25 y 29 años (38\% en Quito y $49 \%$ en Portoviejo), con ingresos entre los USD 601 y USD 1.000 para Quito (26\%) y menores al salario básico en Portoviejo (49\%), y con gastos entre USD 394 y USD 600 en Quito (51\%) y menores al salario básico en Portoviejo (43\%). También se detectó que alrededor del $83 \%$ vecinos estarían dispuestos a colaborar y organizarse en sus barrios para fomentar la inclusión de nuevos residentes, así como participar de procesos de planificación urbana colaborativa.

\section{Escenarios de uso y requerimientos funcionales urbanísticos del MPUC}

Para clarificar los escenarios de uso (EDU) y su despliegue en requisitos funcionales urbanísticos (RFU), se plantean tres dimensiones generales del modelo conceptual de planificación urbana cognitiva: i) acceso a la vivienda (oferta y demanda); ii) urbanismo colaborativo; y iii) toma de decisiones sobre planificación urbana y vivienda. Los RFU habilitan la siguiente etapa de arquitectura cognitiva relacionada al diseño del prototipo y cada escenario de uso ha sido pensado para la interacción en tiempo real entre los usuarios y el prototipo. Además, cabe mencionar que uno de los elementos claves de los RFU para el acceso a la vivienda es la reputación de los usuarios ${ }^{6}$. A continuación se detallan los 11 escenarios de uso dentro de las dimensiones del MPUC y los requisitos funcionales urbanísticos que nos permiten entender el propósito de cada EDU y sus condiciones de cumplimiento:

La dimensión de acceso a la vivienda se refiere a las interacciones mediante las cuales se demandan varios tipos de soluciones habitacionales y a la oferta de bienes o servicios que suplen dichas demandas, estableciéndose cinco escenarios. El EDU-1 involucra al ciudadano que desea mejorar su vivienda, ante lo cual surge el RFU de recomendación del constructor 0 técnico de construcción para realizar los trabajos de renovación. Si se cumple este RFU, el ciudadano podría cumplir además su aspiración de permanecer en el barrio. El EDU-2 involucra a aquel ciudadano que aspira construir su vivienda, con el RFU de recomendación de un constructor para ejecutar los trabajos. El EDU-3 involucra al constructor o técnico de la construcción que oferta sus servicios; para que el escenario se cumpla, el RFU consiste en las recomendaciones realizadas por usuarios que previamente hayan utilizado tal servicio. Para que su reputación sea positiva, el constructor debe cumplir a satisfacción los trabajos

\footnotetext{
${ }^{6}$ Esta reputación implica tanto el rating de la oferta, la cual se refiere al tiempo de servicio, la calidad del servicio, el ahorro en costos, etc., como la fiabilidad de la demanda, es decir, la seriedad con la que se cumplen los acuerdos, incluidas las citas, la conservación del inmueble, tramitología, pagos a tiempo, etc.
} 


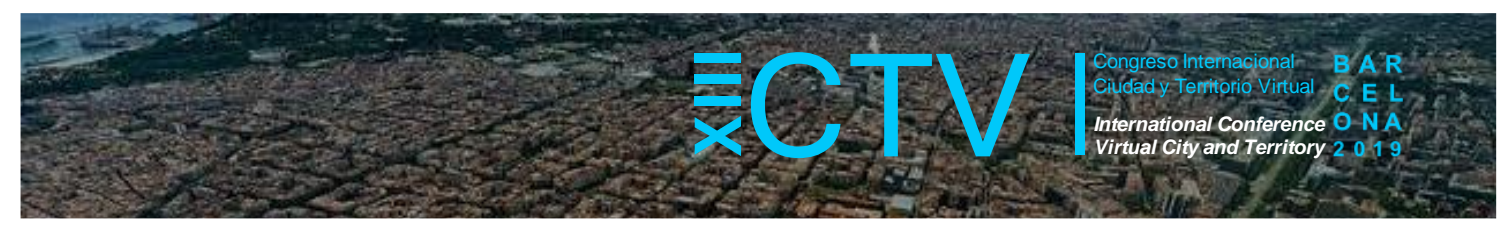

encargados. El EDU-4 considera a los ciudadanos que requieren comprar o alquilar una vivienda. Para el cumplimiento de este escenario, el RFU parte de la recomendación sobre las características deseadas de la vivienda (número de habitaciones, precio, ubicación, etc.) y del sector o barrio (seguro, cercano al trabajo, etc.). Además, el propietario debe tener un nivel de reputación alto para que el sistema lo recomiende, incrementando así sus posibilidades de ser seleccionado. Un EDU-5 considera al propietario que quiere vender o alquilar su vivienda. En este caso, el RFU establece las recomendaciones sobre la fiabilidad del usuario que requiere comprar o alquilar.

La dimensión central de urbanismo colaborativo contempla dos escenarios de uso, a través de los cuales busca relacionar, por una parte, a los ciudadanos que desean participar en la cocreación de su habitar urbano, y por otro lado, a los que desean asistir a los nuevos residentes en sus barrios de acogida. EI EDU-6 incluye al ciudadano que desea cooperar en el desarrollo urbano de su barrio, y al equipo técnico del municipio. Para su cumplimiento, el RFU se basa en la posibilidad de participación del usuario en dos matrices de ámbitos urbanísticos: matriz de reporte de incidencias o eventos que impactan en el entorno construido, y matriz de elaboración de propuestas para la mejora del entorno urbano; en ambos casos, se requiere el procesamiento municipal. El EDU-7 considera al ciudadano que desea asistir a los nuevos vecinos del barrio; con lo cual, se plantea un RFU de vinculación entre el residente del barrio voluntario y el nuevo vecino, con el fin de establecer un tipo de colaboración entre sí, que promueva la participación, y el uso y apropiación del espacio urbano en el ejercicio del derecho a la ciudad en la práctica.

La tercera dimensión del MPUC para el diseño del prototipo comprende la toma de decisiones en torno a la planificación urbana y la vivienda; en ella interactúan los directivos y técnicos municipales con los ciudadanos, y contiene cuatro escenarios de uso. El EDU-8 abarca la necesidad de priorización de ejecución obras y diseño de proyectos para el desarrollo urbano. Para este escenario, el RFU considera que el municipio podrá revisar, sistematizar y procesar las problemáticas de la ciudad asociadas a un ámbito urbanístico, por tipo, localización, intensidad, magnitud, etc.; con la condición de existir disponibilidad de información fiable otorgada por los ciudadanos, así como, de los recursos municipales.

EI EDU-9 considera la necesidad de diseñar los instrumentos de planificación del territorio, para solventar la actualización de lineamientos de uso y ocupación del suelo. De aquí, se plantea un RFU de aprovisionamiento y reporte de información al municipio, consistente en un sistema georreferenciado de acceso a la vivienda y urbanismo colaborativo, asociado a perfiles socioeconómicos ciudadanos. Un EDU-10 parte del interés municipal por generar programas participativos para implementar proyectos urbanísticos de interés común, generando un esquema de planificación urbana colaborativa. Frente a esto, se propone un RFU de participación ciudadana para la valoración y la construcción colectiva de propuestas municipales; para lo cual, el prototipo debe contar con un conjunto de vecinos localizados que se hayan registrado para cooperar en el desarrollo urbano de su entorno. El EDU-11 detecta la necesidad de generar instrumentos de gestión del suelo en relación a la estructura predial, el financiamiento del desarrollo urbano, y la regulación del mercado del suelo. Situación que sugiere un RFU de facilitación en la toma de decisiones, a partir de niveles altos de transparencia en la información generada en el prototipo, por ejemplo, sobre el valor de transacción real en las operaciones de compra-venta y alquiler de vivienda. 


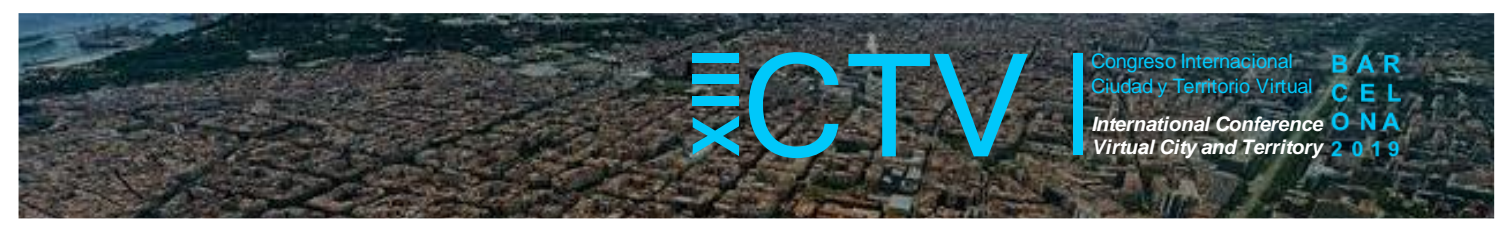

En conclusión, cada escenario de uso asociado a su requerimiento funcional urbanístico ha permitido al equipo de arquitectura cognitiva avanzar con los requerimientos inteligentes del modelo, los cuales se traducen en los primeros diseños del prototipo, junto con los algoritmos cognitivos basados en procesos de Machine Learning, Natural Language Processing, Image Analytics y Speech Analytics. En la Figura 3 se muestran algunos ejemplos del prototipo no operacional que permitió reflejar las condiciones funcionales del modelo teórico llevado al sistema de información, este es el punto de partida para proseguir con la etapa de entrada de información y experimentación del prototipo con la ciudadanía. Allí se observan 6 ejemplos de pantalla: 3a) Recomendación de vivienda en venta en un sector de la ciudad. 3b) Si el usuario es clasificado por el sistema como potencial vecino voluntario se le recomienda un nuevo residente para que se pueda iniciar el proceso de barrio de acogida. 3c) Formulario para que el ciudadano reporte un evento asociado a un ámbito urbanístico. 3d) Facilidad para que el ciudadano participe en propuestas de la comunidad. 3e) Dependiendo del ámbito y tipo de incidencia, el sistema lo asigna a determinados entes gubernamentales para su seguimiento $3 f$ ) Información acerca de proyectos urbanísticos propuestos por el gobierno local para la participación de los usuarios.

Figura 3. Ejemplo de diseño inicial del prototipo

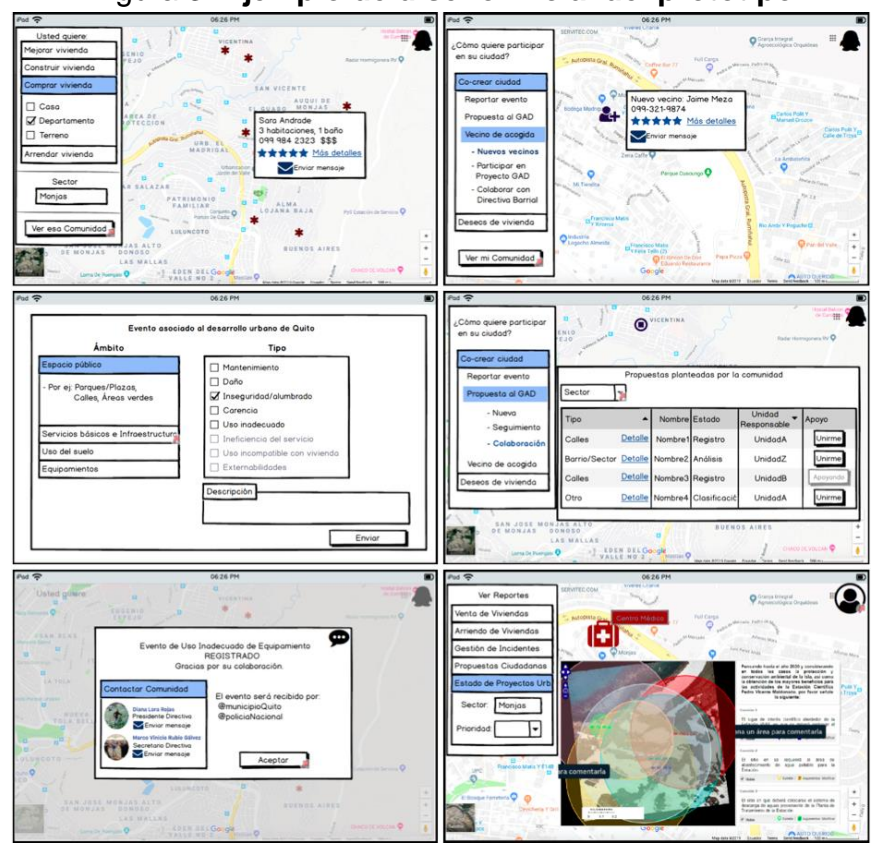

Fuente: Proyecto de Investigación INÉDITA “Planificación Urbana Cognitiva”.

Los medios de aprendizaje evolucionan con el acompañamiento de la tecnología en la mayoría de sus procesos. Comunidades de aprendizaje en redes sociales y humanas, diversos usos del conocimiento colectivo, entre otros, son varias de las alternativas que presentan los sistemas informáticos para el cultivo de datos que hace de sus algoritmos más inteligentes. Estamos estudiando estas capacidades cognitivas en el campo de la planificación urbana con el objetivo de desarrollar entornos en los que los vecinos produzcan su espacio cotidiano. Esta propuesta se guía hacia el desarrollo de una plataforma de cooperación, donde la co-creación de ciudad apoyada por tecnología inteligente sea una realidad concreta. 


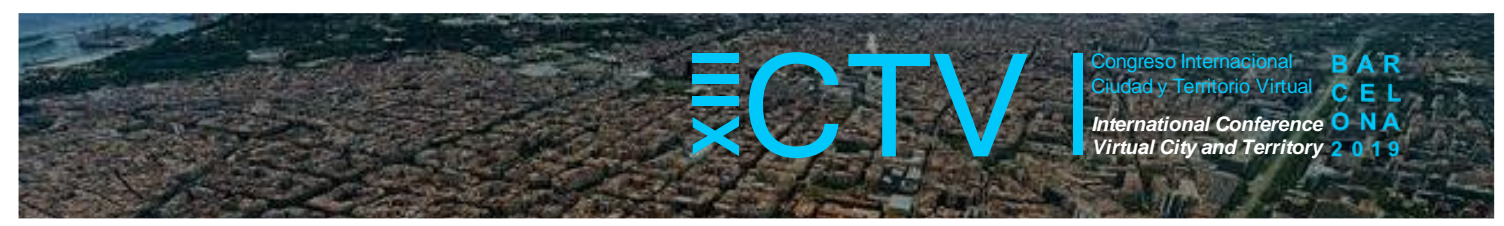

Agradecimientos: Este artículo es posible en el marco del Proyecto de investigación interuniversitario "Planificación Urbana Cognitiva" ganador del concurso INÉDITA, promovido por la Secretaría Nacional de Educación Superior, Ciencia y Tecnología del Ecuador. El levantamiento de la información estuvo a cargo de estudiantes del Instituto Tecnológico Metropolitano de Quito y de la Universidad Técnica de Manabí, entrenados por el equipo de Participación ciudadana del proyecto.

Contribuciones de los autores: El primer y segundo autor han desarrollado en conjunto la totalidad del artículo, el tercer autor ha dado apoyo en parte de la tabulación de resultados de las encuestas, el diseño de los prototipos a partir de los RFU, la edición y recomendaciones finales, el cuarto autor ha contribuido en las secciones 2 y 5 , y en la edición y recomendaciones finales.

Conflicto de Intereses: Los autores declaran que no hay conflicto de intereses.

\section{Bibliografía}

Asobanca. (2019, Enero). Boletín Macroeconómico. Quito, Ecuador. Recuperado de https://www.asobanca.org.ec

Cohen, L., Manion, L., \& Morrison, K. (2007). Research methods in education (6th ed.). New York, US: Routledge/Taylor \& Francis Group.

Finger, M., \& Portmann, E. (2016). What Are Cognitive Cities? En Towards Cognitive Cities: Advances in Cognitive Computing and its Application to the Governance of Large Urban Systems (Vol. 63, pp. 1-11). Cham, Suiza: Springer.

Meza, J. et al. (2019). La planificación urbana colaborativa en la era de las ciudades cognitivas. En Grupo Tecma Red S.L. (Eds.), V Congreso Ciudades Inteligentes (pp. 95-100). Madrid, España: Grupo Tecma Red S.L.

MIDUVI. (2015). Proyecto Programa Nacional de Vivienda Social. (sin número). Recuperado de https://www.habitatyvivienda.gob.ec

Mostashari, A. et al. (2011). Cognitive cities and intelligent urban governance. Network Industries Quarterly, 13(3), 4-7.

Organización de las Naciones Unidas. (2017). United Nations Conference on Housing and Sustainable Urban Development. Habitat III Issue Papers (New York, US: United Nations, 2017). Recuperado de www.habitat3.org

Portugali, J. (2000). Spatial Cognitive Dissonance and Socio-spatial Emergence in a SelfOrganizing City. En Self-Organization and the City (pp. 141-173). Berlín, Alemania: Springer.

Siemens, G. (2005). Connectivism: A learning theory for the digital age. International Journal of Instructional Technology and Distance Learning. elearnspace.org. Recuperado de http://citeseerx.ist.psu.edu/

Thagard, P. (2016). Emotional cognition in urban planning. En: J. Portugali \& E. Stolk (Eds.). Complexity, cognition, urban planning and design (pp. 197-213). Berlín, Alemania: Springer.

UN-HABITAT. (2011). Affordable Land and Housing in Latin America and the Caribbean. En Adequate Housing Series (Vol. 1). Nairobi, Kenia. Recuperado de www.unhabitat.org 